\title{
Advances in Dental Implant Positioning Techniques and Their Clinical Implications
}

\author{
Abdul Aziz Al Sawai' ${ }^{1}$ C. S. Rajmohan ${ }^{2 *}$, Hussein Labib ${ }^{3}$, Said Tabiuk1 \\ ${ }^{1}$ Ministry of Health, Muscat, The Sultanate of Oman \\ ${ }^{2}$ Department of Adult Restorative Dentistry, Oman Dental College, Muscat, The Sultanate of Oman \\ ${ }^{3}$ Consultant Dental Implantologist, Dubai, United Arab Emirates \\ Email: *csrajmohan@staff.omandentalcollege.org
}

How to cite this paper: Al Sawai, A.A., Rajmohan, C.S., Labib, H. and Tabiuk, S. (2017) Advances in Dental Implant Positioning Techniques and Their Clinical Implications. Open Journal of Stomatology, 7, 121-135.

https://doi.org/10.4236/ojst.2017.72008

Received: January 12, 2017

Accepted: February 21, 2017

Published: February 24, 2017

Copyright (C) 2017 by authors and Scientific Research Publishing Inc. This work is licensed under the Creative Commons Attribution International License (CC BY 4.0).

http://creativecommons.org/licenses/by/4.0/

\begin{abstract}
Background: Advancing surgical reconstructive methods and demanding prosthetics need accurate and precise implant placements. Positioning dental implant is vital in both prosthetic and aesthetic perspectives. The optimal three-dimensional placement not only reduces biomechanical complications but also imprecates the odds of implant failure. Materials \& Methods: By using robust text mining, searching and retrieval tools, 350 relevant articles were found and then out of them 161 articles were short listed for our review. They included systematic reviews, meta-analyses, case series and experimental studies. Conclusions \& Results: Conventional freehand implant placement techniques remain experts' favorite for uncompromised cases. However, for compromised cases that demand accuracy and predictability, various computer-based methods are in use. While computerized tomography techniques and use of interactive software prevalent in treatment planning, computer-aided design or computer-aided manufacturing (CAD/ CAM) fabricated surgical guides enable implantologists for more successful implantations.
\end{abstract}

\section{Keywords}

Implant Positioning, Treatment Planning, Implant Surgery,

Computer-Guided Implant Placement

\section{Introduction}

For many edentulous patients, implants remain as a more reliable, functional and aesthetic alternative compared to the traditionally used prosthetic appliances. An increasing demand for implant-retained restorations has resulted in a need for new techniques to ensure proper implant positioning. 
The definition of a successful implant has been refined from just achieving effective osseointegration to a precise positioning and good prosthetic outcome. To achieve such outcomes, use of appropriate treatment planning is increasingly becoming popular. Suitable treatment plans aid in placing the implants in an optimal position, as dictated by the function and aesthetics of the definitive restoration, and to avoid biomechanical complications and failure [1]. The application of computers to various fields of dentistry has led to many advances [2]. One among them is computer-guided implant placement [3]. The aim of this work is to critically review the evolution and clinical implications of various dental implant placement techniques with a special focus on computer-guided implant placement techniques.

\section{Materials and Methods}

By using robust text mining, searching and retrieval tools, including Science Direct and Google Scholar, 350 relevant articles were found. Different combinations of the following keywords were used: dental implants, complications, treatment planning, freehand surgery, and stereolithographic templates. Experimental studies with small sample size ( $<5$ individuals), single case reports and articles written in languages other than English were excluded. There were 161 shortlisted articles that included systematic reviews, meta-analyses, case series and experimental studies.

\section{Discussion}

\subsection{Complications of Improper Implant Positioning}

Most of the reviews illustrated a strong correlation between improper implant position and the marginal bone loss (BL). There are two main explanations found in the literature for the BL. One is disuse atrophy due to subnormal mechanical stimulation [4] and another reason is microgap coming close the bone [5].

It has been shown by many authors [5] [6] that, next to BL, incorrect angulation of the implant often leads to periimplant bone destruction and mechanical complications. As early as 2004, Buser et al. reported that the labial improper placement not only leads to labial bone thinning but also lingual BL and gum recession [7]. It is notable that thinning of the lingual bone, as demonstrated by Tarnow and Eskow (1995), results in emergence problems [8].

Placing the implant both too close or too far apically often cause resorption. The former is investigated in detail by Esposito et al. (1993) which explained the resorption of the interproximal alveolar crest [9] and the latter is studied by Buser et al. (1991) that showed bone resorption [10]. A study by Thilander et al. (1999) has established that the incorrect implant placement near the adjacent teeth not only leads to interproximal BL but also causes tooth vitality loss [11].

Various works also report injuries due to serious complication of mandibular implant osteotomy. For example, Bartling et al. (1999) have reported that the inferior alveolar nerve injury can lead to altered sensation of the lower lip [12]. 
Vazquez et al. (2000) also have explained that such injuries can take place if the magnification factor on the panoramic radiograph is misinterpreted [13].

Similar injuries of mental nerves also frequently reported. Bartling et al. (1999) studied such injuries and demonstrated the importance of correctly locating mental foramen, which can vary from the mandibular canine to the first molar, during surgical procedures in the lower premolar area [12]. Later Grenstein et al. (2006) illustrated the use of CT scans for efficiently detecting the mental foramen than conventional 2D radiographs [14].

Although not very common, lingual bundle injury due to perforation of the lingual cortex is also reported during the incorrect mandibular implant placement. Kalpidis et al. (2004) established that subsequent profuse bleeding and progressive hematoma expansion may cause displacement of the tongue and the floor of the mouth, leading to fatal airway obstruction [15].

Other rare but serious complications noted in the literature include perforation of the nasal or sinus floor, injury of the salivary glands [16], and mandibular fracture in cases of osteoporotic and atrophied mandibles [17].

\subsection{Quest for Optimal Position}

It is commonly accepted that the ideal implant distribution and placement are critical to ensure the optimal mechanical and aesthetic outcomes of definitive restorations, and to enable patients to maintain proper hygiene. Various works have discussed about what is ideal placement in detail and they are summarized in the following Table 1.

Table 1. Criteria for ideal implant placements.

\begin{tabular}{|c|c|c|}
\hline Criteria & Reasons & Source \\
\hline $\begin{array}{l}\text { Surrounded by bone of uniform volume and } \\
\text { density, with a minimum bone thickness of }>1 \\
\text { mm around the implant body }\end{array}$ & $\begin{array}{l}\text { to provide good support against } \\
\text { multidirectional long-term loading }\end{array}$ & {$[18]$} \\
\hline Placed in the geometric centre of the crown & to reduce off-axis loading & [19] \\
\hline $\begin{array}{l}\text { a minimum distance of } 1-1.5 \mathrm{~mm} \text { between the } \\
\text { implant surface and adjacent teeth or } 3 \mathrm{~mm} \text { in } \\
\text { the case of an adjacent natural tooth }\end{array}$ & $\begin{array}{l}\text { to minimize the potential for damage to } \\
\text { the supporting structures }\end{array}$ & {$[20]$} \\
\hline a minimum interimplant distance of $3 \mathrm{~mm}$ & $\begin{array}{l}\text { to prevent bone resorption between } \\
\text { adjacent implants }\end{array}$ & {$[21]$} \\
\hline $\begin{array}{l}\text { a } 2 \mathrm{~mm} \text { distance as a safety zone between the } \\
\text { implant and the nerve }\end{array}$ & $\begin{array}{l}\text { to avoid nerve injury during } \\
\text { mandibular implant surgery. In the case } \\
\text { of placing any implant anterior to the } \\
\text { mental foramen that is deeper than the } \\
\text { safety zone, the mental foramen must } \\
\text { be explored for an anterior loop }\end{array}$ & {$[22]$} \\
\hline \multicolumn{3}{|c|}{ bone grafting, and other procedures, presurgical to avoid the risk of surgical } \\
\hline $\begin{array}{l}\text { CT examinations should routinely be } \\
\text { performed }\end{array}$ & $\begin{array}{l}\text { complications during implant } \\
\text { placement }\end{array}$ & {$[23]$} \\
\hline $\begin{array}{l}\text { CT should be used to verify the presence of the } \\
\text { mandibular lingual vascular canal }\end{array}$ & $\begin{array}{l}\text { to evaluate the lingual cortical bone } \\
\text { thickness and density, to avoid perfora- } \\
\text { tions and life-threatening } \\
\text { bleeding }\end{array}$ & {$[24]$} \\
\hline Multiple implants should be placed in parallel, & to avoid unfavourable off-axis loading & {$[25]$} \\
\hline
\end{tabular}


Not only just the implant placement but also their distribution is studied in details by various experts. The antero-posterior implants and implant- and tissue-supported overdentures are few cases where both the placement and the distributions become critical. The former is studied by Palmqvist et al. (2007) who have emphasized the importance of allowing equal distribution of the load over a wide area with minimal cantilever length [26]. Jivraj S. et al. (2006) enunciated that the implants in the case of implant and tissue-supported over dentures, must be placed such that a constructed bar has a straight-line connection between the implants and does not encroach on the palatal/lingual denture-bearing area with adequate space for the clip. They have further explained the importance of placing more implants when the clinician anticipates high force on the implants from the opposing occlusion to share the load [27].

In addition with satisfying these ideal conditions, it is commonly found in literature that in the case of anterior mandible implant, all preventive measures should be taken before, during, and after implant placement. Experts commonly agree that the surgeon should be skilled and aware of the regional arterial anatomy. Proper treatment planning should also be ensured through radiographic and clinical evaluation of the osseous morphology and finally an implant of the correct angulation and length should be selected.

\subsection{Importance of Treatment Planning}

The careful evaluation of the surgical site and the interaction between the restorative dentists and dental surgeon leads to appropriate treatment planning. There are wide varieties of traditional tools for treatment planning available. They include panoramic, cephalometric and periapical radiographic films, diagnostic wax-ups, and articulated study models [28] [29]. Other diagnostic aids like photography and the ridge-mapping (RM) technique is very useful for assessing the implant bone site. Direct measurement of ridge size remains as the most accurate diagnostic tool but can only be performed during surgery. Ridge size can also be measured using linear tomography or cone-beam CT, but these techniques often lead to under or over-estimation respectively [30] [31].

Being an invasive procedure, RM is difficult to be used in the cases of shallow labial, lingual vestibules. Moreover, RM cannot be used to verify the actual position of the inferior alveolar nerve.

Most of the times the information pertaining to treatment planning required to be collected before surgery to avoid unexpectedly complication surgeries (such as bone harvesting) and to increase treatment predictability. Conventional 2D radiography remains as an important treatment tool but before using but before using one has to be aware of its diagnostic limitations in terms of magnification, distortion, setting errors, and position artifacts [32]. For example, 2D radiographs do not show the lingual anatomy or provide the complete 3D information about the dental arch [33].

Placing the optimal number/size of implants to achieve optimal prosthetic 
outcomes remains as the goal of preoperative implant treatment planning. This necessitates a thorough knowledge of the patient's 3D bony anatomy. This in turn enable the clinician to evaluate the suitability of the remaining bone for implant placement, regarding whether there is sufficient bone volume (BV), bone density (BD), and an appropriate axis of orientation [32].

The use of CT in implant dentistry has tremendously improved treatment planning. CT can be used to identify dental-related jaw anomalies [34] and to determine the optimal implant size and angulation, to avoid injury of critical structures [22] [24]. By allowing visualization of the scanned jaw bone in crosssectional, axial, and panoramic views, CT enables the precise planning of implant placement relative to the bone and future prosthesis, especially when a radiographic template is used [34]. However, the 2D nature of the CT scan still requires the clinician to integrate the images in his mind to gain the desired information in $3 \mathrm{D}$ [35]. However the recent advances in computational methods offer promising solution to overcome this barrier.

\subsection{Interactive Software Programs}

There are number of clinical computer applications developed to allow clinicians to obtain 3D models and plan virtual situations [36]. These programs are increasingly used as tools for implant diagnosis, planning, and treatment execution. In addition to their use with imaging techniques, interactive software programs are used to construct surgical templates for transferring the planned treatment to the patient's mouth [37]. Various commercial software programs are available, most of which display an axial cut, a panoramic cut, and multiple bucco-lingual (parasagittal) cuts [38]. These tools often provide a reformatted 3D image [39], in which the bony structures are visualized with the possibility of incorporating other anatomical structures or soft tissues [37].

\subsubsection{Measuring Bone Density}

Apart from offering plethora of visualizing tools, technology enables clinician to measure bone density (BD). As BD corresponds to bone quality, it is crucial for the success of dental implants [40]. Site-specific measurements of BD provide information for evaluating how long the interval between the first and second stages of surgery should be [41]. An accurate preoperative measurement of the BD helps to prevent the placement of implants in areas of poor quality. Use of CT with interactive software is a viable and accurate method to measure BD [42]. Recent efforts in oral imaging have focused on developing automatic tools to measure BD by $\mathrm{x}$-ray absorption methods [43]. Owing to such efforts, CT images containing BD data in DICOM format are now available, enabling different software programs to measure this parameter [42].

\subsubsection{Estimating Bone Graft Volume}

Software programs in implant dentistry can also be used to evaluate the BV. A lack of sufficient BV frequently precludes conventional implant placement, necessitating the use of augmentation procedures [44]. Detailed preoperative in- 
formation about the needed BV can aid the surgeon in determining the best donor site [45], estimating the volume of xenographic bone substitute required [46], and minimizing the surgery duration, risk of complications, and patient expense [47]. Through software programs, the BV needed to be augmented can be calculated from cross-sectional CT images [48].

\subsection{Recent Developments in Implant Surgery: Applications of Modern Technology}

Recent technological developments paved way for more advancements in restoration and implants. Few of such major areas include: flapless implant surgery, immediate restoration and zygomatic implants.

\subsubsection{Flapless Implant Surgery}

The traditional implant protocol set by Branemark required a few months for osseointegration of the end osseous implants before the definitive dental prostheses could be installed [49]. With the advent of modern technology, including $\mathrm{CT}$, interactive software programs, and CAD/CAM-fabricated surgical guides, the development of "flapless" implant surgery has been made possible [50]. The goal of this minimally invasive surgical technique is to reduce treatment costs and patient healing time. Implants placed without flap elevation show increased osseointegration and periimplant bone height compared to implants placed with flap elevation [51]. Moreover, the resulting small, clean, closed wounds heal quickly with little scar formation, compared to large open wounds that heal slowly and with significant scarring.18 D.C. Sabiston and H.K. Lyerly, Textbook of 4 surgery", Saunders, The biological basis of modern surgical practice, Philadelphia (1997) p. 207-220.

Flapless implant surgery is a popular approach with numerous advantages, including improved patient comfort and healing, decreased surgical time, and the ability to resume normal hygiene procedures immediately after surgery. However, this approach is only indicated when the surgeon is confident that the underlying osseous anatomy is ideal relative to the planned implant size, and that its $3 \mathrm{D}$ position in the alveolus. Without these conditions, many problems may arise, including injury of unseen vital structures, thermal damage, malposed angle or depth of implant placement, and inability to contour the osseous topography appropriately to facilitate restorative procedures [52].

\subsubsection{Immediate Restoration}

The precise implant placement offered through the application of modern technologies to dentistry has allowed immediate loading with prefabricated final restorations [53]. For example, the recently introduced "Immediate Smile" treatment protocol allows the simultaneous placement of endosseous implants and a CAD/CAM-guided, immediately loaded, definitive prosthesis [54]. Its viability is supported by its accuracy, which allows the virtually planned 3D model to be transferred to the surgical template, the implants to be placed, and the prosthesis to be attached immediately after abutment connection [53]. 


\subsubsection{Zygomatic Implants}

The use of CT data and interactive software program for treatment planning has made the management of compromised cases much easier and more predictable. For example, sinus pneumatization in a long-term edentulous patient can complicate implant placement. Maxillary sinus-lift procedures are frequently performed to create adequate BV for predictable implant placement [53]. However, these procedures have many disadvantages, including donor site morbidity, long operation time, high cost, and invasiveness [56]. CT is an extremely useful tool for evaluating the bone trajectory in the posterior maxilla. By using information from the CT scan, the implants can be inclined to avoid the maxillary sinuses, and alternative procedures (e.g., using existing anatomical sites) that offer reduced morbidity and minimal invasion of the existing structures may be used [27].

The zygomatic implant is a promising alternative for the management of the severely atrophied maxilla. Zygomatic implants can be placed to engage the zygomatic bone infero-lateral to the orbital rim, to provide anchorage for a fixed prosthesis in conjunction with anterior implants [57]. However, due to the anatomy of the zygomatic bone and the implant length, placement of a zygomatic implant poses a challenge for prosthodontists [58]. Based on computeraided preoperative treatment planning with CT data, stereolithographically produced customized drill guides have been developed to determine the location, angle, and implant insertion depth. This approach provides a link between the planning and actual surgery, by transferring the virtual treatment plan accurately to the patient's mouth [58]. For optimal implant positioning, it is mandatory that the treatment plan be precisely transferred to the patient's mouth [59]. Two main problems still affect the accuracy of zygomatic implant placement in a severely atrophic edentulous maxilla. The first problem is the stability of the drill guide, which must rest on the underlying tissue. An unstable surgical guide will negatively affect the accuracy of translation of the preoperative treatment planning to the operative field [13] [19] C.C. Galanis, M.M. Sfantsikopoulos, P.T. Koidis, N.M. Kafantaris and P.G. Mpikos, «Computer methods for automating preoperative dental 4implant planning: ‘implant positioning and size assignment, Comput. Methods Programs Biomed.86 (2007), pp. 30-38. Article | 츠 PDF $(665 \mathrm{~K}) \mid$ View Record in Scopus|Cited By in Scopus (6). The second problem is the manual placement of the implant; currently, guidance is only provided for drilling and not for implant placement [58].

\subsection{Computer-Guided Implant Placement}

The technology is playing a vital role also in optimally placing implants. There are number of issues with freehand implant placements and various tools have been proposed to overcome them.

\subsection{Computer-Guided versus Freehand Implant Placement}

In freehand implant placement, execution of the treatment plan is guided by 
mental navigation [58], which inevitably leads to inaccuracies in implant positioning. For example, a study of implant positioning in the posterior maxilla found that only $20 \%$ of freehand-placed implants could be categorized as "ideally placed" [60]. The use of conventionally constructed surgical templates cannot ensure placement accuracy if the created holes or slots do not guarantee the correct axis of the intrabony implants, and they cannot ensure parallelism when multiple implants are placed [61].

These templates only guarantee that the entry point of the drill is at the ridge crest, which later is translated as the position of the implant head [33]. However, it is misleading to judge the position of the implant through the location of its head at the bone crest. Additionally, the parallel appearance of multiple implants on $2 \mathrm{D}$ radiographs does not mean that they are actually parallel. Finally, nearly five drills are used in the conventional freehand protocol, any of which may deviate from the original plan, resulting in unguided implant placement in the prepared implant site [54].

In computer-guided implant placement, the accuracy can be judged by comparing the postoperative outcome to the recorded preoperative 3D plan [62]. However, in freehand implant placement, there is no accurate preoperative plan to compare the postoperative outcome against [50]. Even when CT scans and software programs are used to create a preoperative treatment plan, the freehand placement will always deviate from the ideal position in the preoperative plan [63]. Moreover, although researchers agree on the value and necessity of accuracy, there is no clear consensus as to its definition or the parameters used to evaluate it [58]. Furthermore, a universal and absolute value (in millimeters) for an "acceptable" deviation cannot be defined, because even the smallest deviation might be significant in some clinical situations (e.g., nerve injury) [27].

\subsubsection{Tools for Computer-Guided Implant Placement}

Three tools for computer-guided implant placement have been reported in the literature: robots, navigation, and CAD/CAM-generated stereolithographic surgical guides (SSGs). Robots are accurate tools to transfer the treatment plan to patients; however, their high cost and low availability limit their use [62]. Navigation systems permit improved precision of insertion in terms of the position, angulation, and depth of implant placement compared to conventional freehand placement [64]. Protocols using a navigation system reportedly result in similar accuracies compared to protocols using CAD/CAM-developed SSGs [65]. Park et al. (2009) compared the accuracy of 45 implants placed on a manikin through a CAD/CAM-fabricated surgical template to freehand placement [40]. The lateral deviation and angulation of the implant axis were reduced in the CAD/ CAM-guided implants compared to the freehand-placed implants. Accuracy was improved when the guidance extended to the implant placement itself and not the drilling guidance alone. The horizontal deviation was minimized, the implant angulation was more accurate, and the implant depth was fully controlled by specially designed stoppers on the drills and the implant holder. Nickenig et 
al. (2009) achieved similar results in their study of 23 implants in 10 patients [62].

Historically, implants were placed without the use of surgical guides; however, increased demands for more appropriate implant positioning has led to surgical guide development [56]. Surgical guide fabrication begins with a diagnostic tooth positioning, either through a waxing, denture tooth arrangement, or duplication of the preexisting teeth or restorations [66]. SSGs are precise metallic guides that are closely matched in diameter to the drills or implants [63]. They are fabricated through CAD/CAM technology and rapid prototyping machines [67]. Resin is laser-polymerized layer-by-layer at 1-mm thickness, which corresponds to the slice interval in the CT-formatting process. Usually, they are made in sets of three, each incorporating metal sleeves (5 $\mathrm{mm}$ in height) and different diameters corresponding to the diameters of the surgical drills [34]. They can be fabricated to fit to bone, teeth, and/or mucosa, per the surgeon's request [54].

The surgical guide can guide both the drills and the implant placement. Only two drills are used (the pilot and the final drill), which have depth-control stops and are stepped such that they can be guided through the same guiding tube. Because the same drill can be used to drill osteotomies of different depths, the surgical guide is fabricated so that different guiding tubes are placed at different heights to adapt to the depth difference of the osteotomies. Drilling is performed until the drill is blocked by the depth-control stops. By using the same surgical guide, the implants can be placed, and the depth of implant placement can be secured through the specially designed, differently sized implant holders [54].

\subsubsection{Benefits and Limitations of Computer-guided Implant Placement}

The main benefit of CAD/CAM-guided dental implant planning and placement is that it allows thorough preoperative diagnostics and a more predictable implantation procedure [58]. It reduces the risk of damage to adjacent structures [56], and permits the implementation of restorative goals through accurate presurgical planning [34]. In some cases, use of these systems may allow bone augmentation procedures to avoided (e.g., by utilizing present bone) or flapless surgery to be considered [52]. Use of an accurate surgical guide permits the implants to be placed precisely into planned positions, which may allow the immediate delivery of a prefabricated final prosthesis [69].

However, computer-guided implant placement has some [36] limitations, including a high treatment cost (i.e., due to the software purchase, radiographic template and SSG fabrications, and CT scan) and the high radiation dose of the CT scan [36]. The radiation risk can be reduced by lowering the dose output of the scanner [70] and using modern scanners, which produce lower radiation doses. Some authors [62] [71] [72] recommend the use of cone-beam CT, which can decrease both the cost and radiation dose.

Under/overestimation of the BV during CT-driven treatment planning and virtual implant planning may reduce the predictability of implant positioning. 
This problem might by overcome by increasing the resolution of the CT data and using sufficient exposure during scanning [31]. An inaccurate CT scan [63] and lack of stability or reproducibility of the radiographic template during CT will lead to improperly scanned data for treatment planning, with subsequently incorrect clinical implant positioning.

A poorly fitted or unstable surgical guide will affect the precision of implant placement. Poor access in posterior areas can result from the large surgical guide thickness or guiding cylinder height. Limited interocclusal space in the posterior segments is problematic and may make drill insertion through the surgical guide impossible, necessitating freehand implant placement. Poor visibility during drilling can make it difficult to verify the proper drilling depth and perform instrumentation, especially in posterior areas [69]. Heat generation in the drill, due to the enclosure of the drill within the guiding cylinder of the surgical guide, can also lead to implant failure.

\section{Conclusions \& Results}

Based on the available data, CT scanning and interactive software programs for the treatment planning and fabrication of CAD/CAM-based SSGs appear to be viable and promising tools that may improve the predictability, safety, and precision of implant placement compared to conventional freehand placement. The high accuracy of computer-guided implant placement may facilitate the clinical management of complicated cases. Moreover, the high accuracy and precision of transferring the treatment plan to the patient's mouth makes the immediate delivery of a prefabricated final prosthesis a reliable option.

However, computer-guided implant placement is not without limitations. It is a technique-sensitive procedure, involving the creation of studying models, diagnostic wax-ups, and radiographic templates, CT scanning, interpretation of CT data, treatment planning, and the fabrication and stabilization of a surgical guide in the patient's mouth during surgery. An error at any of these steps may affect the accuracy and precision of implant placement. Although computerguided implant placement is a promising technology, its performance must be critically evaluated, particularly because this technique is already commercially available and used by many clinicians. Given the limited data, relatively short observation periods, and lack of randomized controlled trials available in the literature, prospective clinical studies with long-term follow-ups should be performed. Such studies should strive to improve the systems and procedures with respect to their accuracy, predictability, and reproducibility of implant placement, as well as the surgical and prosthetic outcomes.

\section{References}

[1] Kopp, K.C., Koslow, A.H. and Abdo, O.S. (2003) Predictable Implant Placement with a Diagnostic/Surgical Template and Advanced Radiographic Imaging. Journal of Prosthetic Dentistry, 89, 611-615. https://doi.org/10.1016/S0022-3913(03)00198-7 
[2] Schleyer, T.K.L., Thyvalikakath, T.P., Spallek, H., Torres-Urquidy, M.H., Hernandez, P. and Yuhaniak, J. (2006) Clinical Computing in General Dentistry. Journal of the American Medical Informatics Association, 13, 344-352. https://doi.org/10.1197/jamia.M1990

[3] Azari, A. and Nikzad, S. (2008) Computer-Assisted Implantology: Historical Background and Potential Outcomes-A Review. The International Journal of Medical Robotics \& Computer Assisted Surgery, 4, 95-104. https://doi.org/10.1002/rcs.188

[4] Bartling, R., Freeman, K. and Kraut, R.A. (1999) The Incidence of Altered Sensation of the Mental Nerve after Mandibular Implant Placement. Journal of Oral and Maxillofacial Surgery, 57, 1408-1410. https://doi.org/10.1016/S0278-2391(99)90720-6

[5] Vidyasagar, L. and Apse, P. (2004) Dental Implant Design and Biological Effects on Bone-Implant Interface. Stomatologija, 6, 51-54.

[6] Saab, X.E., Griggs, J.A., Powers, J.M. and Engelmeier, R.L. (2007) Effect of Abutment Angulation on the Strain on the Bone around an Implant in the Anterior Maxilla: A Finite Element Study. The Journal of Prosthetic Dentistry, 97, 85-92. https://doi.org/10.1016/j.prosdent.2006.12.002

[7] Buser, D., Martin, W. and Belser, U.C. (2004) Optimizing Esthetics for Implant Restorations in the Anterior Maxilla: Anatomic and Surgical Considerations. International Journal of Oral \& Maxillofacial Implants, 19, 43-61.

[8] Tarnow, D. and Eskow, R. (1995) Considerations for Single-Unit Esthetic Implant Restorations. Compendium of Continuing Education in Dentistry, 16, 778, 780, 782-784.

[9] Esposito, M., Ekestubbe, A. and Grondahl, K. (1993) Radiological Evaluation of Marginal Bone Loss at Tooth Surfaces Facing Single Branemark Implants. Clinical Oral Implants Research, 4, 151-157. https://doi.org/10.1034/j.1600-0501.1993.040306.x

[10] Buser, D., Schenk, R.K., Steinemann, S., Fiorellini, J.P., Fox, C.H. and Stich, H. (1991) Influence of Surface Characteristics on Bone Integration of Titanium Implants. A Histomorphometric Study in Miniature Pigs. Journal of Biomedical Materials Research, 25, 889-902. https://doi.org/10.1002/jbm.820250708

[11] Thilander, B., Odman, J. and Jemt, T. (1999) Single Implants in the Upper Incisor Region and Their Relationship to the Adjacent Teeth. An 8-Year Follow-Up Study. Clinical Oral Implants Research, 10, 346-355. https://doi.org/10.1034/j.1600-0501.1999.100502.x

[12] Bartling, R., Freeman, K. and Kraut, R.A. (1999) The Incidence of Altered Sensation of the Mental Nerve after Mandibular Implant Placement. Journal of Oral and Maxillofacial Surgery, 57, 1408-1412.

[13] Vazquez, L., Saulacic, N., Belser, U. and Bernard, J.P. (2008) Efficacy of Panoramic Radiographs in the Preoperative Planning of Posterior Mandibular Implants: A Prospective Clinical Study of 1527 Consecutively Treated Patients. Clinical Oral Implants Research, 19, 81-85.

[14] Greenstein, G. and Tarnow, D. (2006) The Mental Foramen and Nerve: Clinical and Anatomical Factors Related to Dental Implant Placement: A Literature Review. Journal of Periodontology, 77, 1933-1943. https://doi.org/10.1902/jop.2006.060197

[15] Kalpidis, C.D. and Setayesh, R.M. (2004) Hemorrhaging Associated with Endosseous Implant Placement in the Anterior Mandible: A Review of the Literature. Journal of Periodontology, 75, 631-645. https://doi.org/10.1902/jop.2004.75.5.631

[16] Nahlieli, O., Droma, E.B., Eliav, E., Zaguri, A., Shacham, R. and Bar, T. (2008) Salivary Gland Injury Subsequent to Implant Surgery. The International Journal of Oral 
\& Maxillofacial Implants, 23, 556-560.

[17] Meijer, H.J., Raghoebar, G.M. and Visser, A. (2003) Mandibular Fracture Caused by Peri-Implant Bone Loss: Report of a Case. Journal of Periodontology, 74, 10671070. https://doi.org/10.1902/jop.2003.74.7.1067

[18] Clelland, N.L., Gilat, A., McGlumphy, E.A. and Brantley, W.A. (1993) A Photoelastic and Strain Gauge Analysis of Angled Abutments for an Implant System. The International Journal of Oral \& Maxillofacial Implants, 8, 541-548.

[19] Galanis, C.C., Sfantsikopoulos, M.M., Koidis, P.T., Kafantaris, N.M. and Mpikos, P.G. (2007) Computer Methods for Automating Preoperative Dental Implant Planning: Implant Positioning and Size Assignment. Computer Methods and Programs in Biomedicine, 86, 30-38. https://doi.org/10.1016/j.cmpb.2006.12.010

[20] Adell, R., Lekholm, U., Brånemark, P., Lindhe, J., Rockler, B., Eriksson, B., et al. (1984) Marginal Tissue Reactions at Osseointegrated Titanium Fixtures. Swedish Dental Journal Supplement, 28, 175-181.

[21] Traini, T., Novaes, A.B.J., Papalexiou, V. and Piattelli, A. (2008) Influence of Interimplant Distance on Bone Microstructure: a Histomorphometric Study in Dogs. Clinical Implant Dentistry and Related Research, 10, 1-10. https://doi.org/10.1111/j.1708-8208.2007.00052.x

[22] Buser, D. and Arx, T. (2000) Surgical Procedures in Partially Edentulous Patients with ITI Implants. Clinical Oral Implants Research, 11, 83-100. https://doi.org/10.1034/j.1600-0501.2000.011S1083.x

[23] Ganz, S.D. (2005) Presurgical Planning with CT-Derived Fabrication of Surgical Guides. Journal of Oral and Maxillofacial Surgery, 63, 59-71.

[24] Scaravilli, M.S., Mariniello, M. and Sammartino, G. (2010) Mandibular Lingual Vascular Canals (MLVC): Evaluation on Dental CTs of a Case Series. European Journal of Radiology, 76, 173-176. https://doi.org/10.1016/j.ejrad.2009.06.002

[25] Arfai, N.K. and Kiat-Amnuay, S. (2007) Radiographic and Surgical Guide for Placement of Multiple Implants. Journal of Prosthetic Dentistry, 97, 310-312. https://doi.org/10.1016/j.prosdent.2007.03.002

[26] Palmqvist, S., Sondell, K. and Swartz, B. (1994) Implant-Supported Maxillary Overdentures: Outcome in Planned and Emergency Cases. The International Journal of Oral \& Maxillofacial Implants, 9, 184-190.

[27] Chee, W. and Jivraj, S. (2006) Treatment Planning of the Edentulous Mandible. British Dental Journal, 201, 337-347. https://doi.org/10.1038/sj.bdj.4814041

[28] Becker, C.M. and Kaiser, D.A. (2000) Surgical Guide for Dental Implant Placement. Journal of Prosthetic Dentistry, 83, 248-251. https://doi.org/10.1016/S0022-3913(00)80018-9

[29] Almog, D.M., Torrado, E. and Meitner, S.W. (2001) Fabrication of Imaging and Surgical Guides for Dental Implants. Journal of Prosthetic Dentistry, 85, 504-508. https://doi.org/10.1067/mpr.2001.115388

[30] Perez, L.A., Brooks, S.L., Wang, H.L. and Eber, R.M. (2005) Comparison of Linear Tomography and Direct Ridge Mapping for the Determination of Edentulous Ridge Dimensions in Human Cadavers. Oral Surgery, Oral Medicine, Oral Pathology, Oral Radiology, and Endodontics, 99, 748-754.

[31] Chen, L.C., Lundgren, T., Hallstrom, H. and Cherel, F. (2008) Comparison of Different Methods of Assessing Alveolar Ridge Dimensions Prior to Dental Implant Placement. Journal of Periodontology, 79, 401-405.

https://doi.org/10.1902/jop.2008.070021

[32] Tyndall, D.A. and Brooks, S.L. (2000) Selection Criteria for Dental Implant Site 
Imaging: A Position Paper of the American Academy of Oral and Maxillofacial Radiology. Oral Surgery, Oral Medicine, Oral Pathology, Oral Radiology, and Endodontics, 89, 630-637. https://doi.org/10.1067/moe.2000.106336

[33] Nikzad, S. and Azari, A. (2008) A Novel Stereolithographic Surgical Guide Template for Planning Treatment Involving a Mandibular Dental Implant. Journal of Oral and Maxillofacial Surgery, 66, 1446-1454.

[34] Lal, K., White, G.S., Morea, D.N. and Wright, R.F. (2006) Use of Stereolithographic Templates for Surgical and Prosthodontic Implant Planning and Placement. Part II. A Clinical Report. Journal of Prosthodontics, 15, 117-122.

[35] Hassfeld, S. and Muhling, J. (2001) Computer Assisted Oral and Maxillofacial Surgery-A Review and an Assessment of Technology. International Journal of Oral and Maxillofacial Surgery, 30, 2-13. https://doi.org/10.1054/ijom.2000.0024

[36] Katsoulis, J., Pazera, P. and Mericske-Stern, R. (2009) Prosthetically Driven, Computer-Guided Implant Planning for the Edentulous Maxilla: A Model Study. Clinical Implant Dentistry and Related Research, 11, 238-245. https://doi.org/10.1111/j.1708-8208.2008.00110.x

[37] Schneider, D., Marquardt, P., Zwahlen, M. and Jung, R.E. (2009) A Systematic Review on the Accuracy and the Clinical Outcome of Computer-Guided Template-Based Implant Dentistry. Clinical Oral Implants Research, 20, 73-86. https://doi.org/10.1111/j.1600-0501.2009.01788.x

[38] Engelke, W. and Capobianco, M. (2005) Flapless Sinus Floor Augmentation Using Endoscopy Combined with CT Scan-Designed Surgical Templates: Method and Report of 6 Consecutive Cases. The International Journal of Oral \& Maxillofacial Implants, 20, 891-897.

[39] Parel, S.M. and Triplett, R.G. (2004) Interactive Imaging for Implant Planning, Placement, and Prosthesis Construction. Journal of Oral and Maxillofacial Surgery, 62, 41-47.

[40] Park, H.S., Lee, Y.J., Jeong, S.H. and Kwon, T.G. (2008) Density of the Alveolar and Basal Bones of the Maxilla and the Mandible. American Journal of Orthodontics and Dentofacial Orthopedics, 133, 30-37.

[41] Friberg, B., Sennerby, L., Roos, J. and Lekholm, U. (1995) Identification of Bone Quality in Conjunction with Insertion of Titanium Implants. A Pilot Study in Jaw Autopsy Specimens. Clinical Oral Implants Research, 6, 213-219. https://doi.org/10.1034/j.1600-0501.1995.060403.x

[42] Norton, M.R. and Gamble, C. (2001) Bone Classification: An Objective Scale of Bone Density Using the Computerized Tomography Scan. Clinical Oral Implants Research, 12, 79-84. https://doi.org/10.1034/j.1600-0501.2001.012001079.x

[43] De Oliveira, R.C., Leles, C.R., Normanha, L.M., Lindh, C. and Ribeiro-Rotta, R.F. (2008) Assessments of Trabecular Bone Density at Implant Sites on CT Images. Oral Surgery, Oral Medicine, Oral Pathology, Oral Radiology, and Endodontics, 105, 231-238. https://doi.org/10.1016/j.tripleo.2007.08.007

[44] Esposito, M., Grusovin, M.G., Felice, P., Karatzopoulos, G., Worthington, H.V. and Coulthard, P. (2009) Interventions for Replacing Missing Teeth: Horizontal and Vertical Bone Augmentation Techniques for Dental Implant Treatment. The Cochrane Database of Systematic Reviews, 7, Cd003607.

https://doi.org/10.1002/14651858.cd003607.pub4

[45] Verdugo, F., Simonian, K., Smith McDonald, R. and Nowzari, H. (2009) Quantitation of Mandibular Ramus Volume as a Source of Bone Grafting. Clinical Implant Dentistry and Related Research, 11, e32-e37.

https://doi.org/10.1111/j.1708-8208.2009.00172.x 
[46] Clavero, J. and Lundgren, S. (2003) Ramus or Chin Grafts for Maxillary Sinus Inlay and Local Onlay Augmentation: Comparison of Donor Site Morbidity and Complications. Clinical Implant Dentistry and Related Research, 5, 154-160. https://doi.org/10.1111/j.1708-8208.2003.tb00197.x

[47] Cricchio, G. and Lundgren, S. (2003) Donor Site Morbidity in Two Different Approaches to Anterior Iliac Crest Bone Harvesting. Clinical Implant Dentistry and Related Research, 5, 161-169. https://doi.org/10.1111/j.1708-8208.2003.tb00198.x

[48] Hatano, N., Shimizu, Y. and Ooya, K. (2004) A Clinical Long-Term Radiographic Evaluation of Graft Height Changes after Maxillary Sinus Floor Augmentation with a 2:1 Autogenous Bone/Xenograft Mixture and Simultaneous Placement of Dental Implants. Clinical Oral Implants Research, 15, 339-345. https://doi.org/10.1111/j.1600-0501.2004.00996.x

[49] Lindquist, L.W., Carlsson, G.E. and Jemt, T. (1996) A Prospective 15-Year Follow-Up Study of Mandibular Fixed Prostheses Supported by Osseointegrated Implants. Clinical Results and Marginal Bone Loss. Clinical Oral Implants Research, 7, 329-336. https://doi.org/10.1034/j.1600-0501.1996.070405.x

[50] Sclar, A.G. (2007) Guidelines and Pitfalls of Minimally Invasive and "Flapless" Dental Implant Surgery. Journal of Oral and Maxillofacial Surgery, 65, 9-10. https://doi.org/10.1016/j.joms.2007.06.034

[51] Jeong, S.M., Choi, B.H., Li, J., Kim, H.S., Ko, C.Y., Jung, J.H., et al. (2007) Flapless Implant Surgery: An Experimental Study. Oral Surgery, Oral Medicine, Oral Pathology, Oral Radiology, and Endodontics, 104, 24-28. https://doi.org/10.1016/j.tripleo.2006.11.034

[52] Van de Velde, T., Glor, F. and De Bruyn, H. (2008) A Model Study on Flapless Implant Placement by Clinicians with a Different Experience Level in Implant Surgery. Clinical Oral Implants Research, 19, 66-72.

[53] Malo, P., de Araujo Nobre, M. and Lopes, A. (2007) The Use of Computer-Guided Flapless Implant Surgery and Four Implants Placed in Immediate Function to Support a Fixed Denture: Preliminary Results after a Mean Follow-Up Period of Thirteen Months. Journal of Prosthetic Dentistry, 97, S26-S34. https://doi.org/10.1016/S0022-3913(07)60005-5

[54] Tardieu, P. (2003) Immediate Smile: The State of the Art. Materialise Headlines, 3, 1-3.

[55] Raja, S.V. (2009) Management of the Posterior Maxilla with Sinus Lift: Review of Techniques. Journal of Oral and Maxillofacial Surgery, 67, 1730-1734.

[56] Fortin, T., Isidori, M. and Bouchet, H. (2009) Placement of Posterior Maxillary Implants in Partially Edentulous Patients with Severe Bone Deficiency Using CAD/CAM Guidance to Avoid Sinus Grafting: A Clinical Report of Procedure. The International Journal of Oral \& Maxillofacial Implants, 24, 96-102.

[57] Henry, P.J. (2002) A Review of Guidelines for Implant Rehabilitation of the Edentulous Maxilla. Journal of Prosthetic Dentistry, 87, 281-288.

https://doi.org/10.1067/mpr.2002.122775

[58] Vrielinck, L., Politis, C., Schepers, S., Pauwels, M. and Naert, I. (2003) Image-Based Planning and Clinical Validation of Zygoma and Pterygoid Implant Placement in Patients with Severe Bone Atrophy Using Customized Drill Guides. Preliminary Results from a Prospective Clinical Follow-Up Study. International Journal of Oral and Maxillofacial Surgery, 32, 7-14. https://doi.org/10.1054/ijom.2002.0337

[59] Wanschitz, F., Birkfellner, W., Watzinger, F., Schopper, C., Patruta, S., Kainberger, F., et al. (2002) Evaluation of Accuracy of Computer-Aided Intraoperative Positioning of Endosseous Oral Implants in the Edentulous Mandible. Clinical Oral Im- 
plants Research, 13, 59-64. https://doi.org/10.1034/j.1600-0501.2002.130107.x

[60] Massey, B. and Alder, M. (2002) Analyzing Implant Placement in the Posterior Maxilla. Journal of Dental Research, 81, 1619.

[61] Engelman, M.J., Sorensen, J.A. and Moy, P. (1988) Optimum Placement of Osseointegrated Implants. Journal of Prosthetic Dentistry, 59, 467-473. https://doi.org/10.1016/0022-3913(88)90044-3

[62] Nickenig, H.J., Wichmann, M., Hamel, J., Schlegel, K.A. and Eitner, S. (2010) Evaluation of the Difference in Accuracy between Implant Placement by Virtual Planning Data and Surgical Guide Templates versus the Conventional Free-Hand Method-A Combined in Vivo-in Vitro Technique Using Cone-Beam CT (Part II). Journal of Cranio-Maxillo-Facial Surgery, 38, 488-493.

[63] Park, C., Raigrodski, A.J., Rosen, J., Spiekerman, C. and London, R.M. (2009) Accuracy of Implant Placement Using Precision Surgical Guides with Varying Occlusogingival Heights: An in Vitro Study. Journal of Prosthetic Dentistry, 101, 372-381. https://doi.org/10.1016/S0022-3913(09)60080-9

[64] Casap, N., Tarazi, E., Wexler, A., Sonnenfeld, U. and Lustmann, J. (2005) Intraoperative Computerized Navigation for Flapless Implant Surgery and Immediate Loading in the Edentulous Mandible. The International Journal of Oral \& Maxillofacial Implants, 20, 92-98.

[65] Ruppin, J., Popovic, A., Strauss, M., Spuntrup, E., Steiner, A. and Stoll, C. (2008) Evaluation of the Accuracy of Three Different Computer-Aided Surgery Systems in Dental Implantology: Optical Tracking vs. Stereolithographic Splint Systems. Clinical Oral Implants Research, 19, 709-716. https://doi.org/10.1111/j.1600-0501.2007.01430.x

[66] Neidlinger, J., Lilie, B.A. and Kalant, D.C. (1993) Surgical Implant Stent: A Design Modification and Simplified Fabrication Technique. Journal of Prosthetic Dentistry, 69, 70-72. https://doi.org/10.1016/0022-3913(93)90243-H

[67] Marchack, C.B. (2007) CAD/CAM-Guided Implant Surgery and Fabrication of an Immediately Loaded Prosthesis for a Partially Edentulous Patient. Journal of Prosthetic Dentistry, 97, 389-394. https://doi.org/10.1016/S0022-3913(07)60028-6

[68] Widmann, G. and Bale, R.J. (2006) Accuracy in Computer-Aided Implant Surgery-A Review. The International Journal of Oral \& Maxillofacial Implants, 21, 305-313.

[69] Yong, L.T. and Moy, P.K. (2008) Complications of Computer-Aided-Design/ Computer-Aided-Machining-Guided (NobelGuide) Surgical Implant Placement: An Evaluation of Early Clinical Results. Clinical Implant Dentistry and Related Research, 10, 123-127. https://doi.org/10.1111/j.1708-8208.2007.00082.x

[70] Ekestubbe, A., Thilander, A., Grondahl, K. and Grondahl, H.G. (1993) Absorbed Doses from Computed Tomography for Dental Implant Surgery: Comparison with Conventional Tomography. Dentomaxillofacial Radiology, 22, 13-17. https://doi.org/10.1259/dmfr.22.1.8508935

[71] Guerrero, M.E., Jacobs, R., Loubele, M., Schutyser, F., Suetens, P. and van Steenberghe, D. (2006) State-of-the-Art on Cone Beam CT Imaging for Preoperative Planning of Implant Placement. Clinical Oral Investigations, 10, 1-7.

[72] Loubele, M., Van Assche, N., Carpentier, K., Maes, F., Jacobs, R., van Steenberghe, D., et al. (2008) Comparative Localized Linear Accuracy of Small-Field Cone-Beam CT and Multislice CT for Alveolar Bone Measurements. Oral Surgery, Oral Medicine, Oral Pathology, Oral Radiology, and Endodontics, 105, 512-518. 
Submit or recommend next manuscript to SCIRP and we will provide best service for you:

Accepting pre-submission inquiries through Email, Facebook, LinkedIn, Twitter, etc. A wide selection of journals (inclusive of 9 subjects, more than 200 journals)

Providing 24-hour high-quality service

User-friendly online submission system

Fair and swift peer-review system

Efficient typesetting and proofreading procedure

Display of the result of downloads and visits, as well as the number of cited articles Maximum dissemination of your research work

Submit your manuscript at: http://papersubmission.scirp.org/

Or contact ojst@scirp.org 